PLATE 1
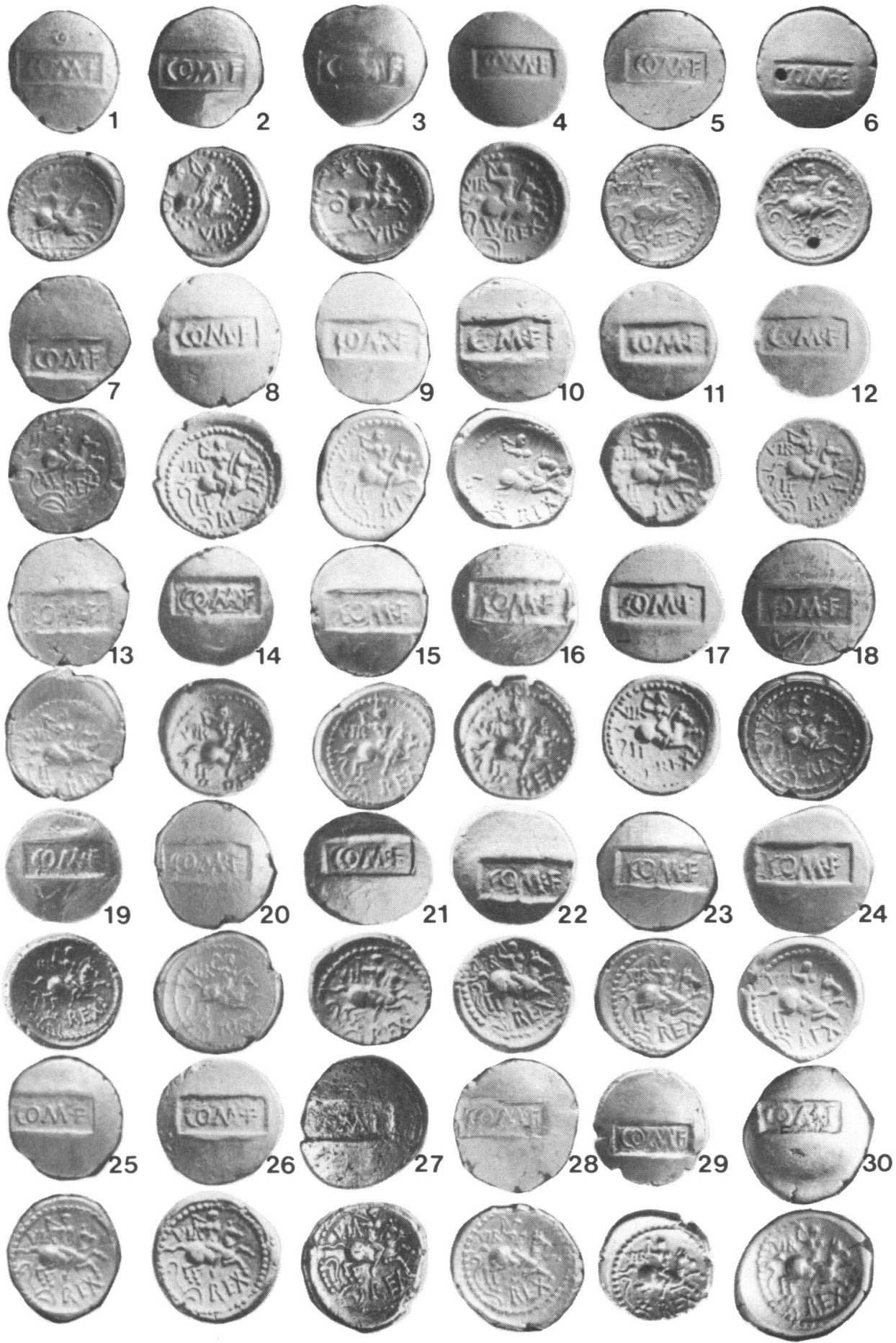

(Photo: Institute of Archaeology, Oxford)

Gold Coins of Verica, Nos. 1-30 (Scale 1:1).

See pp. 9-10 for description. 
PLATE II

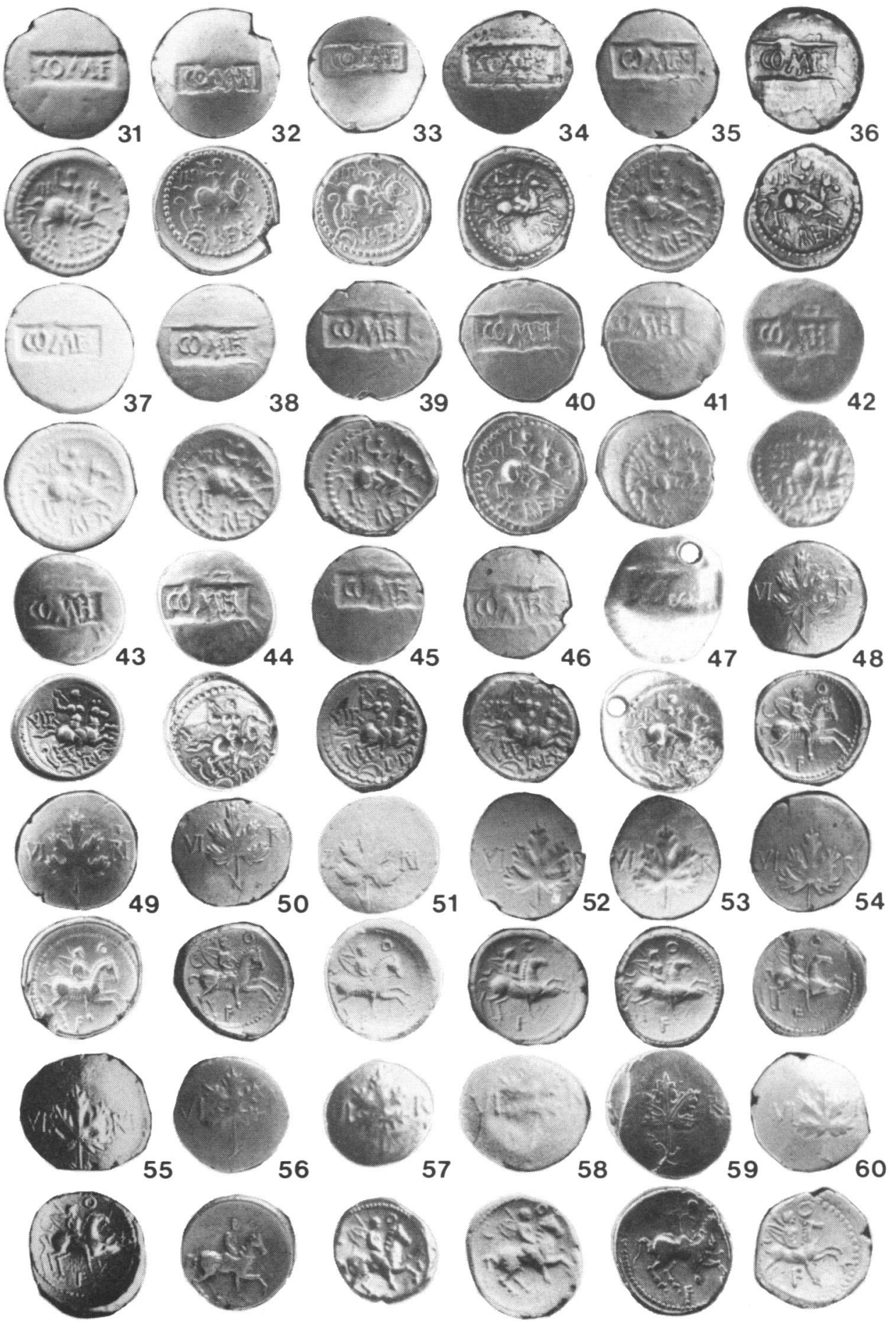

(Pholo: Institute of Archaeology, Oxford)

Gold Coins of Verica, Nos. 31-60 (Scale 1:1)

See pp. 10-11 for description. 
PLATE III
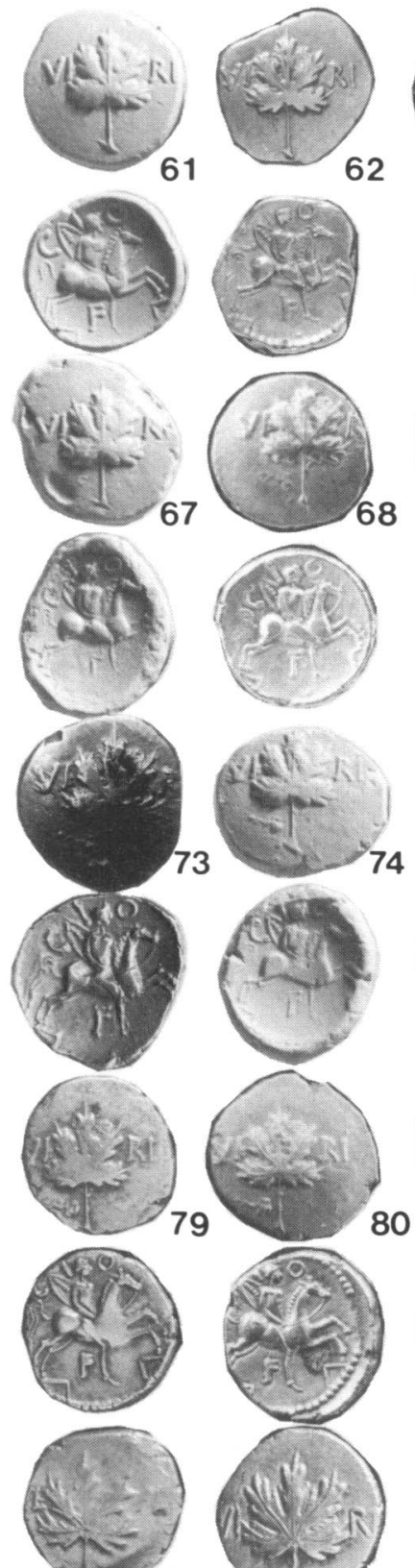

85
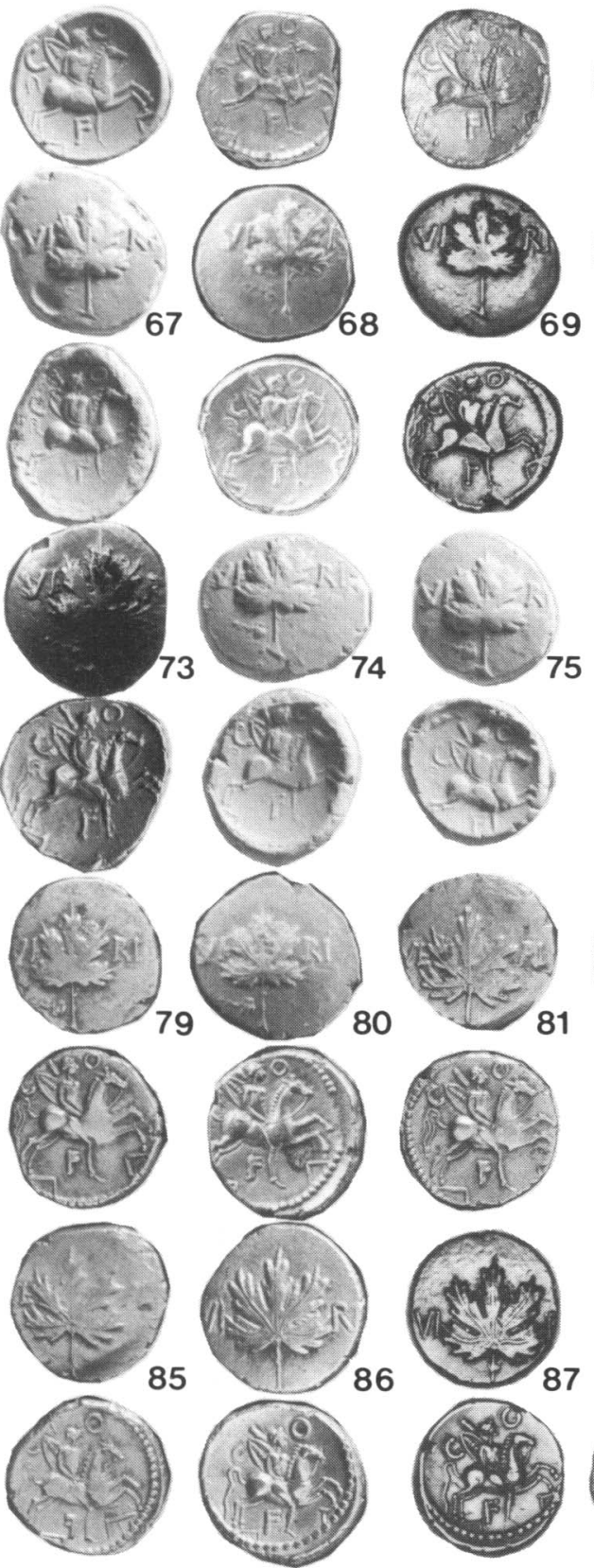
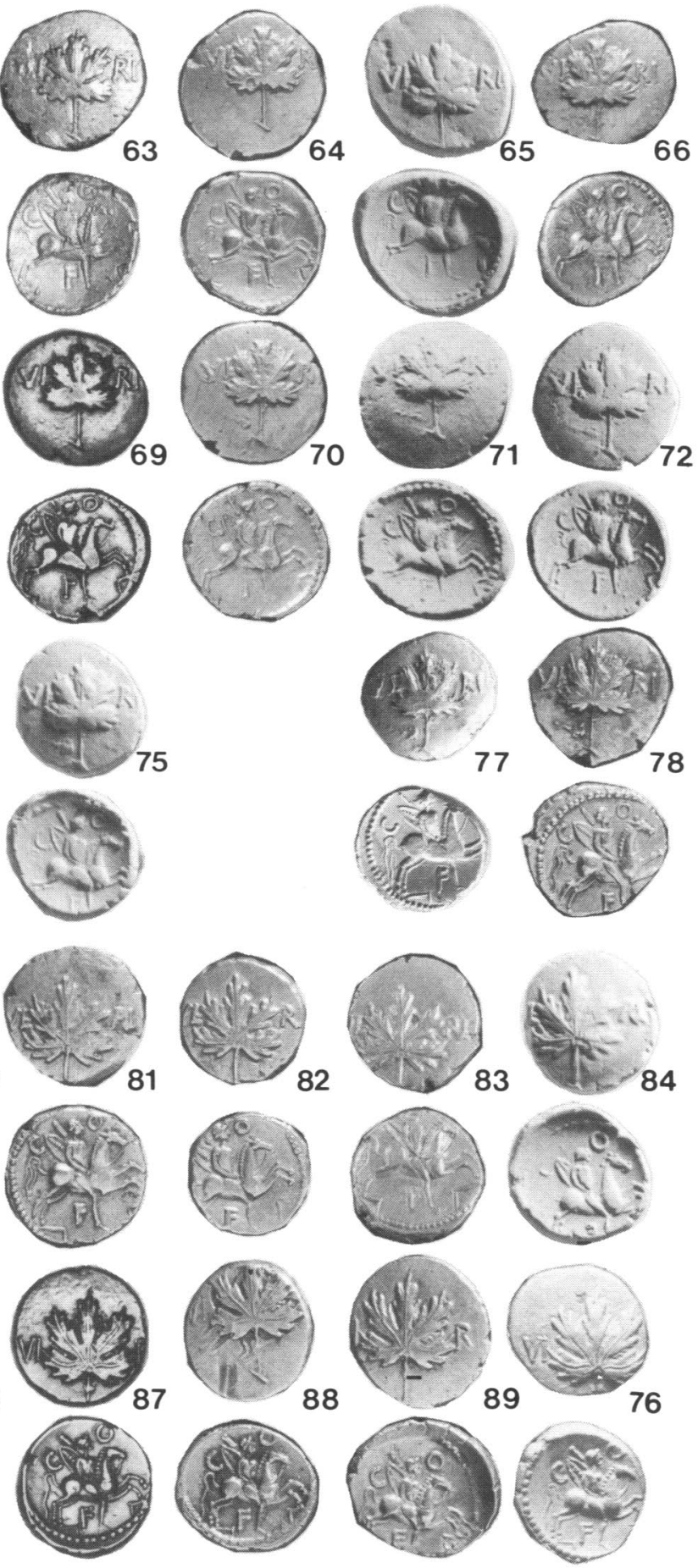

(Photo: Institute of Archaeology, Oxford)

Gold Coins of Verica, Nos. 61-75, 77-89, and 76 .

See p. 11 for description. 
PLATE IV
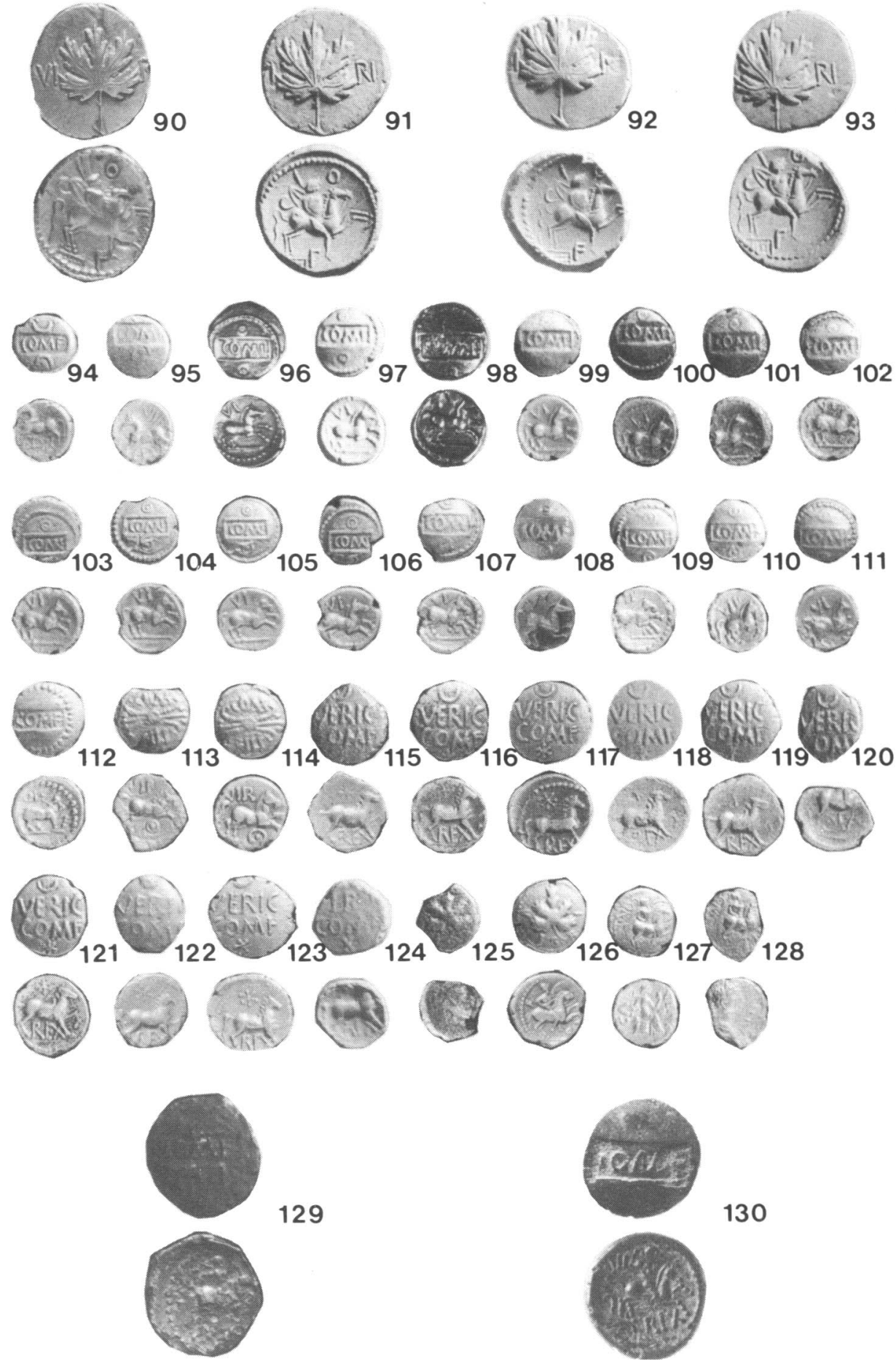

(Photo: Instirute of Archaeology, Oxford)

Gold Coins of Verica, Nos. 90-130.

See pp. 11-14 for description. 


\section{PLATE V}

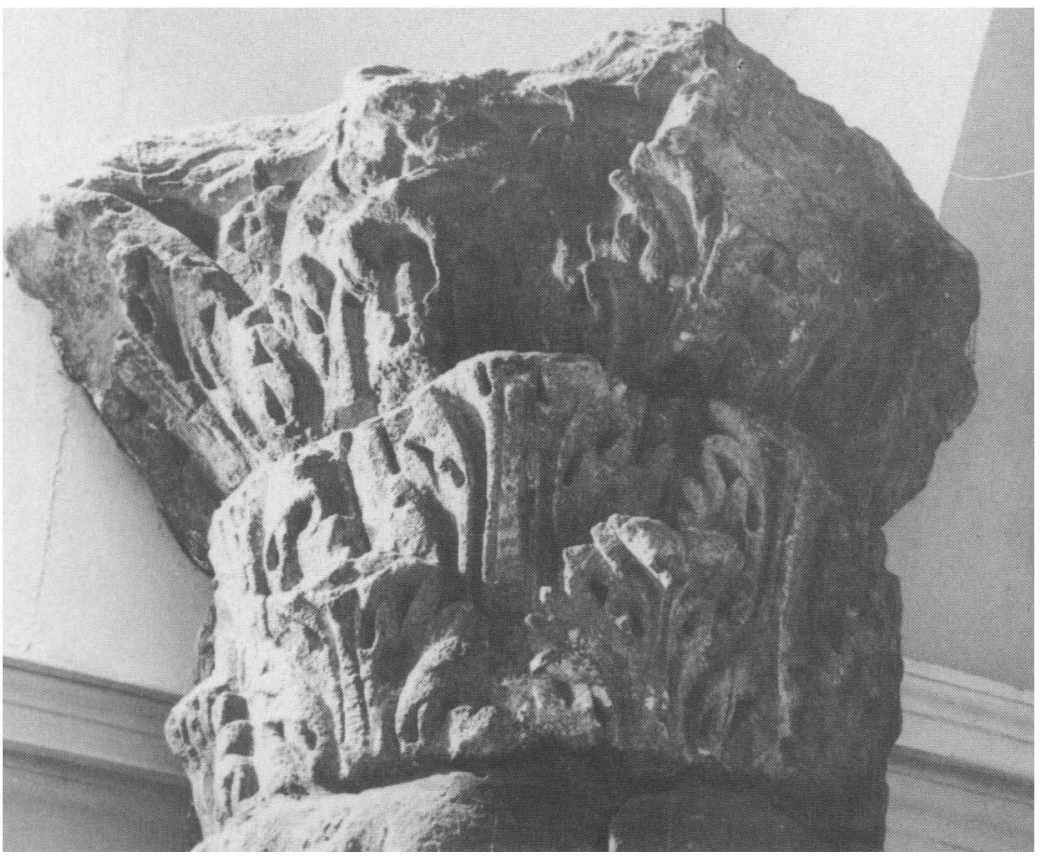

(Photo: T. F. C. Blagg)

A. Temple of Sulis Minerva at Bath: the Corinthian Capital (p. 101).

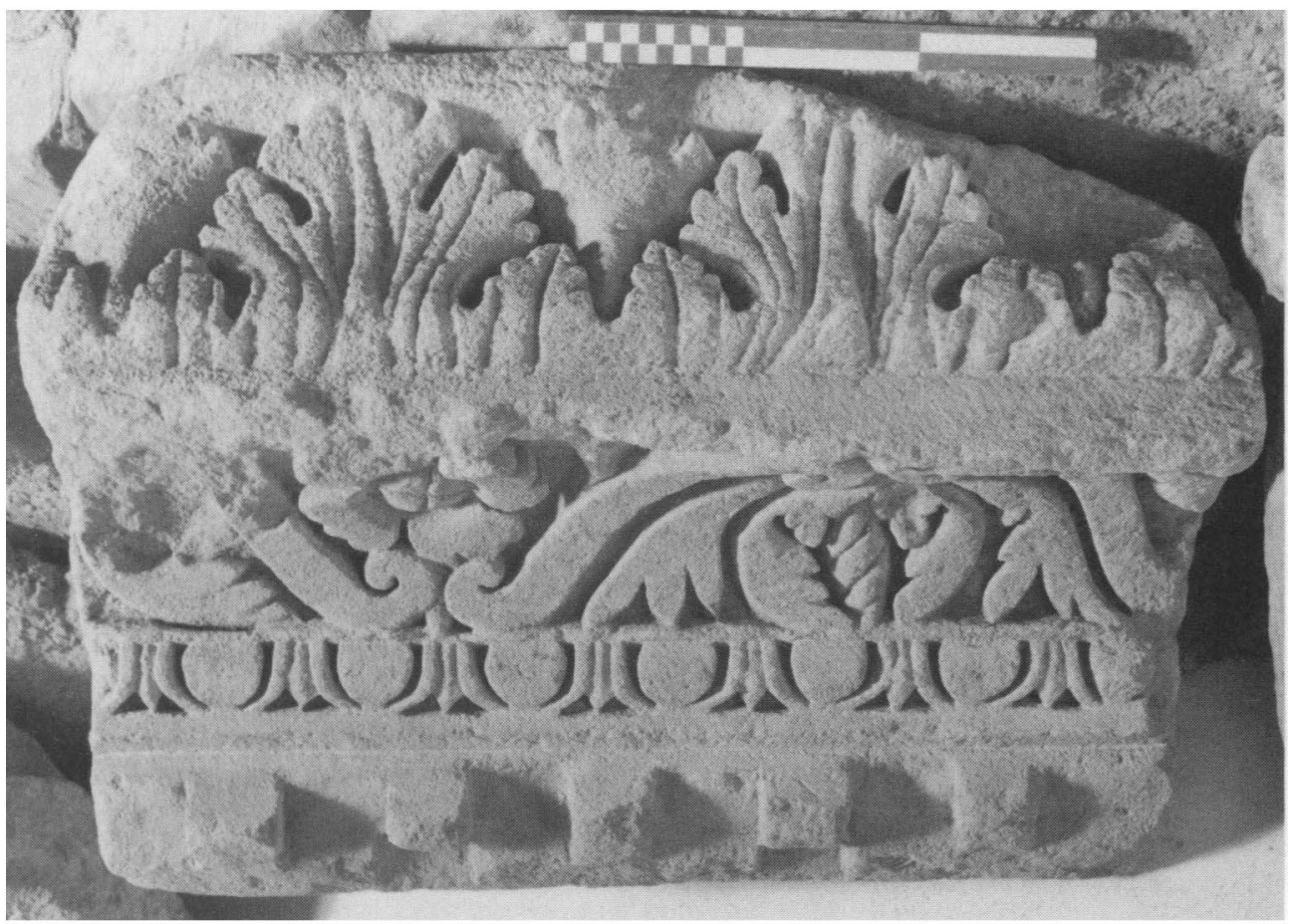

(Photo: R. Wilkins)

B. Temple of Sulis Minerva at Bath: the Cornice (p. 104). 
PLATE VI

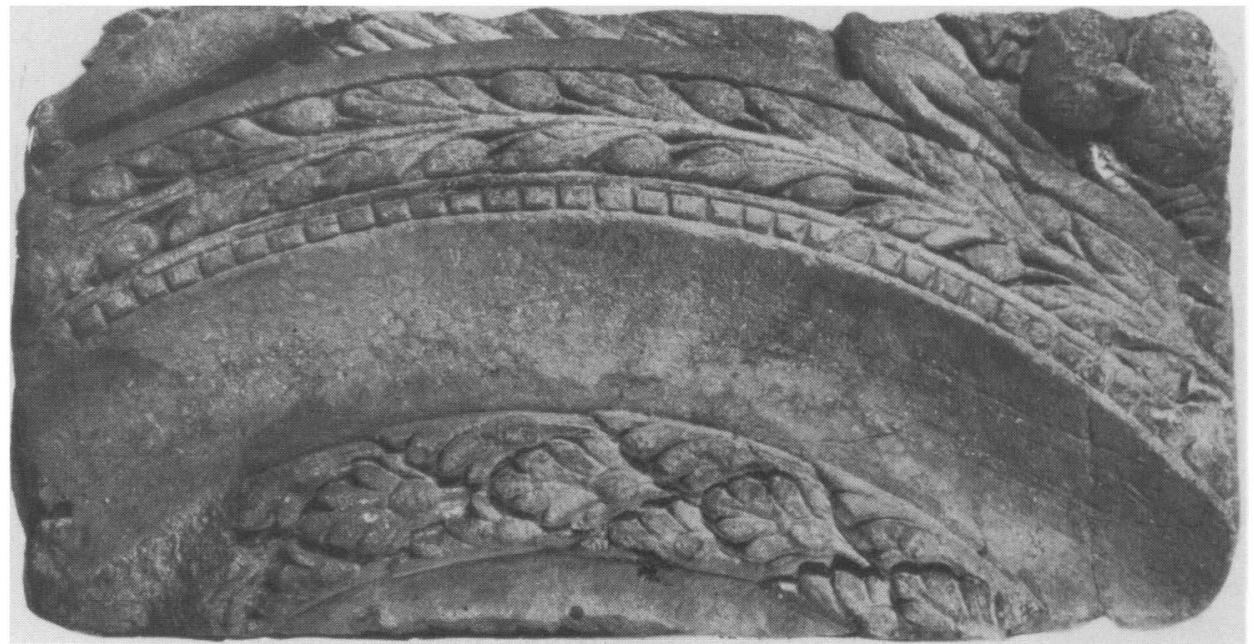

(Photo: R. Wilkins)

A. Temple of Sulis Minerva at Bath: the Gorgon Pediment, detail of the ornament (p. 106).

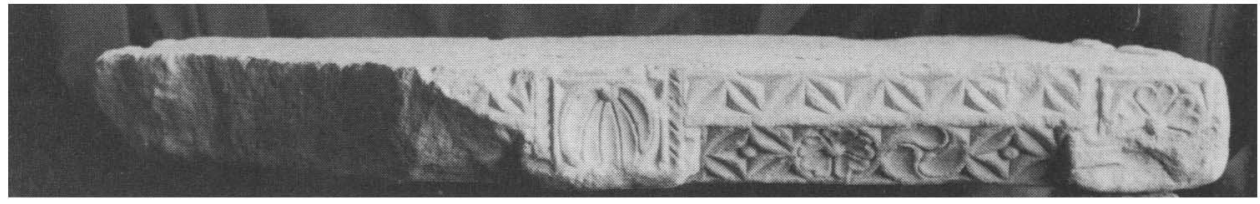

(Photo: A. T. Morley Hewitt)

B. Stone Table-top No. 16 from West Park Villa, Rockbourne, Hants. (p. 169). Scale c. 1:6.

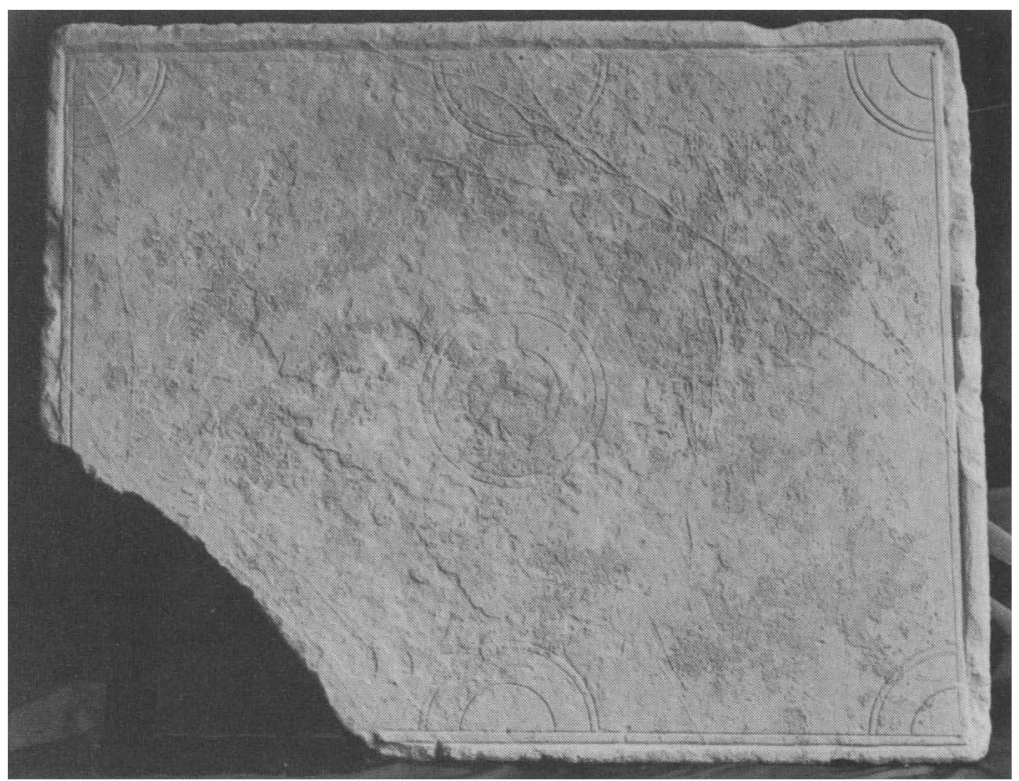

(Photo: A. T. Morlev Hewitt)

C. The same, showing decoration on surface (p. 169). Scale $c$. $1: 7$. 


\section{PLATE VII}

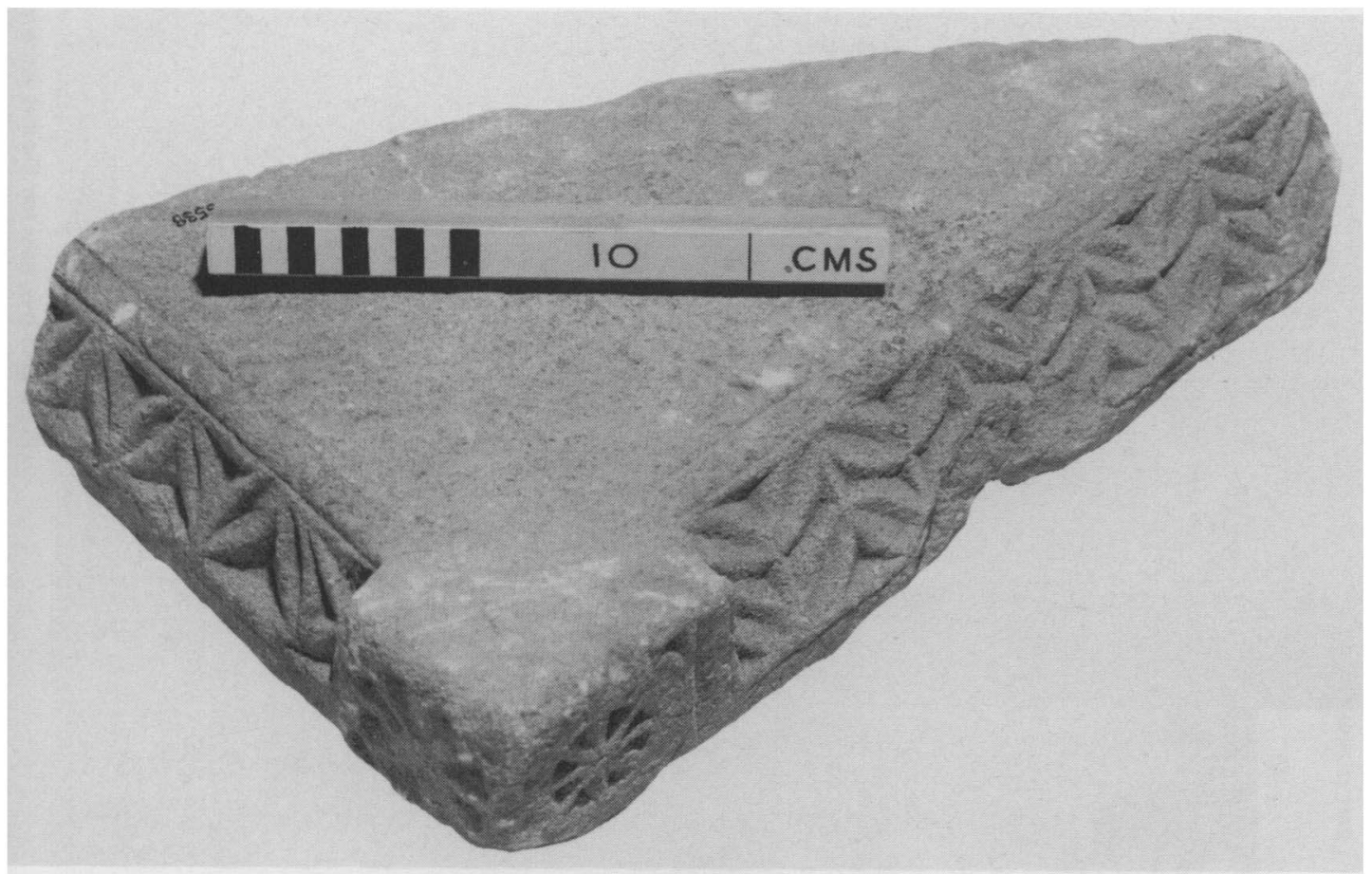

(Photo: City Museum, Bristol)

A. Stone Table-top No. 1 (1) from Gatcombe, Avon (p. 169).

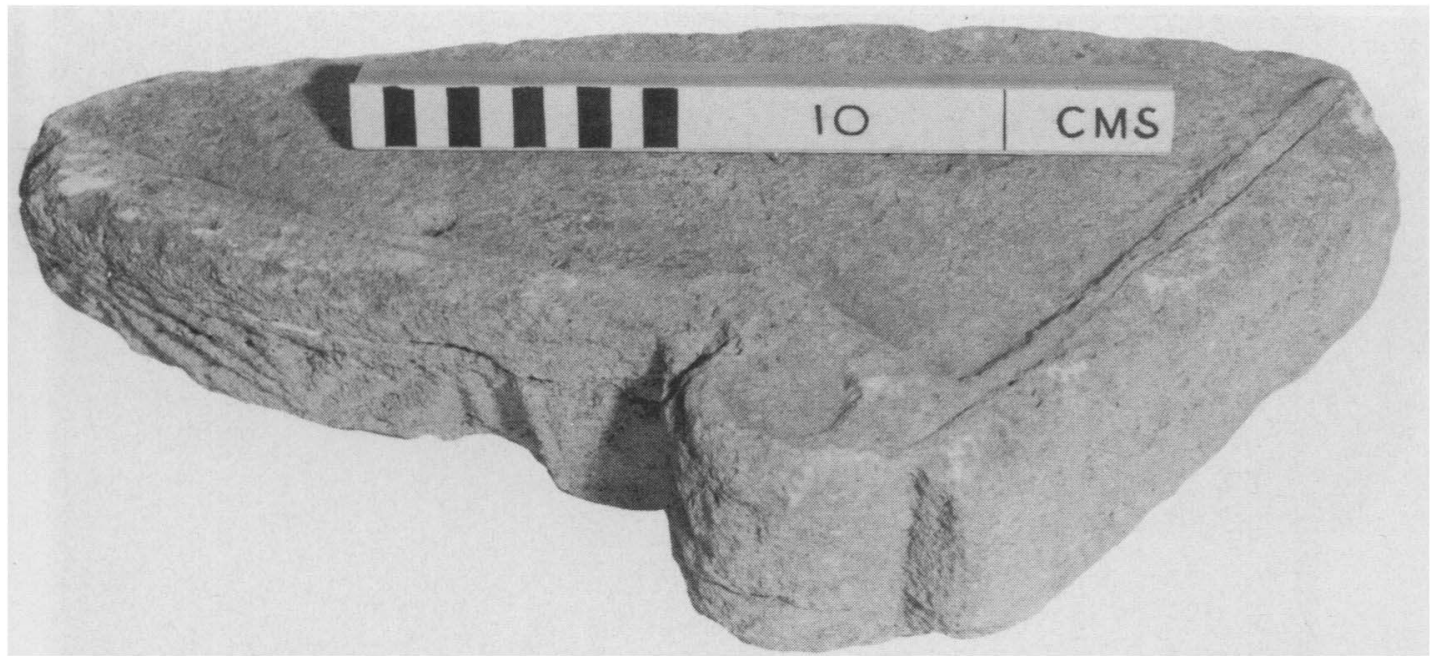

(Photo: City Museum, Bristol)

B. Stone Table-top No. 1 (2) from Gatcombe, Avon (p. 175). 
PLATE VIII
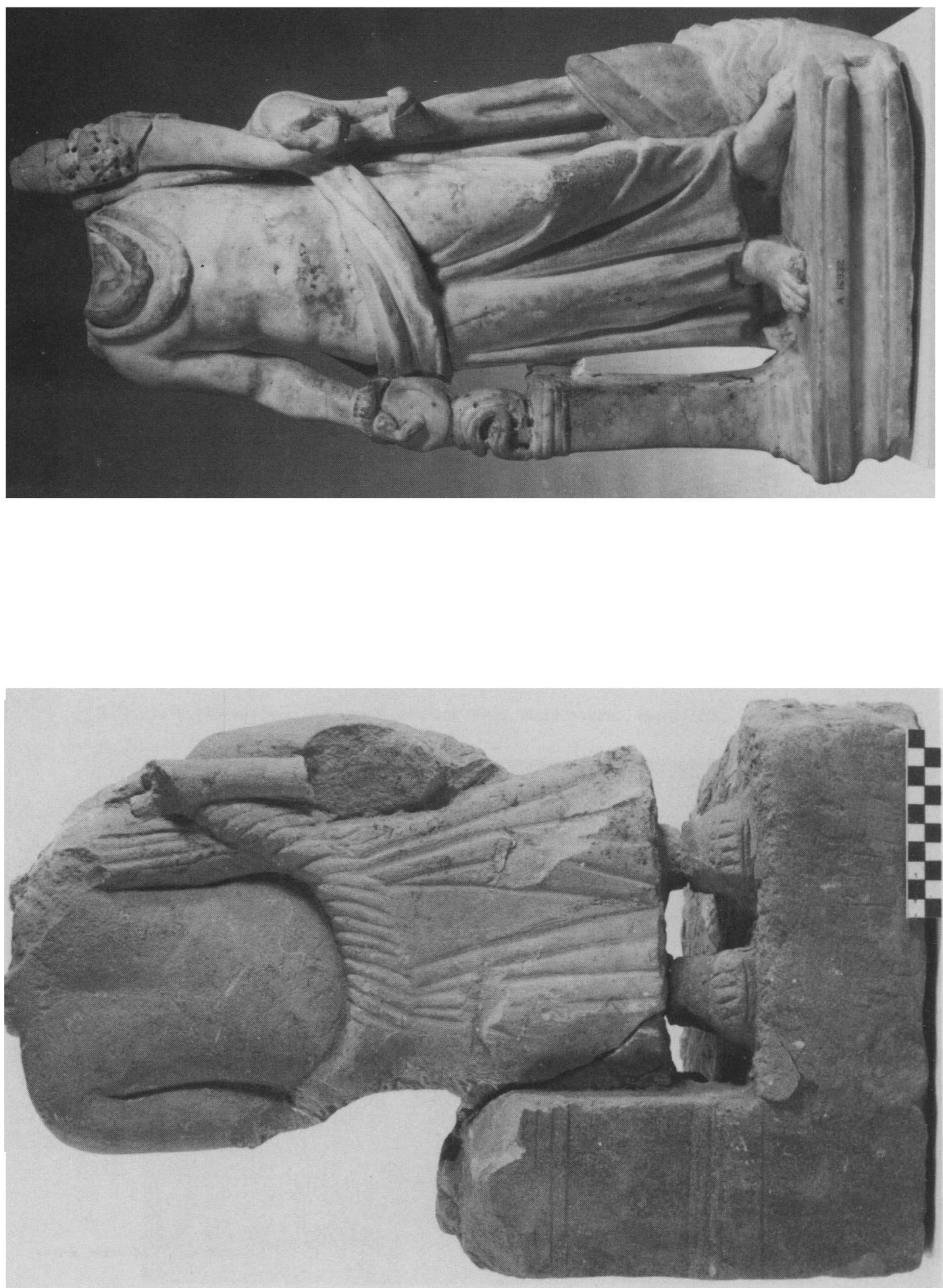
PLATE IX

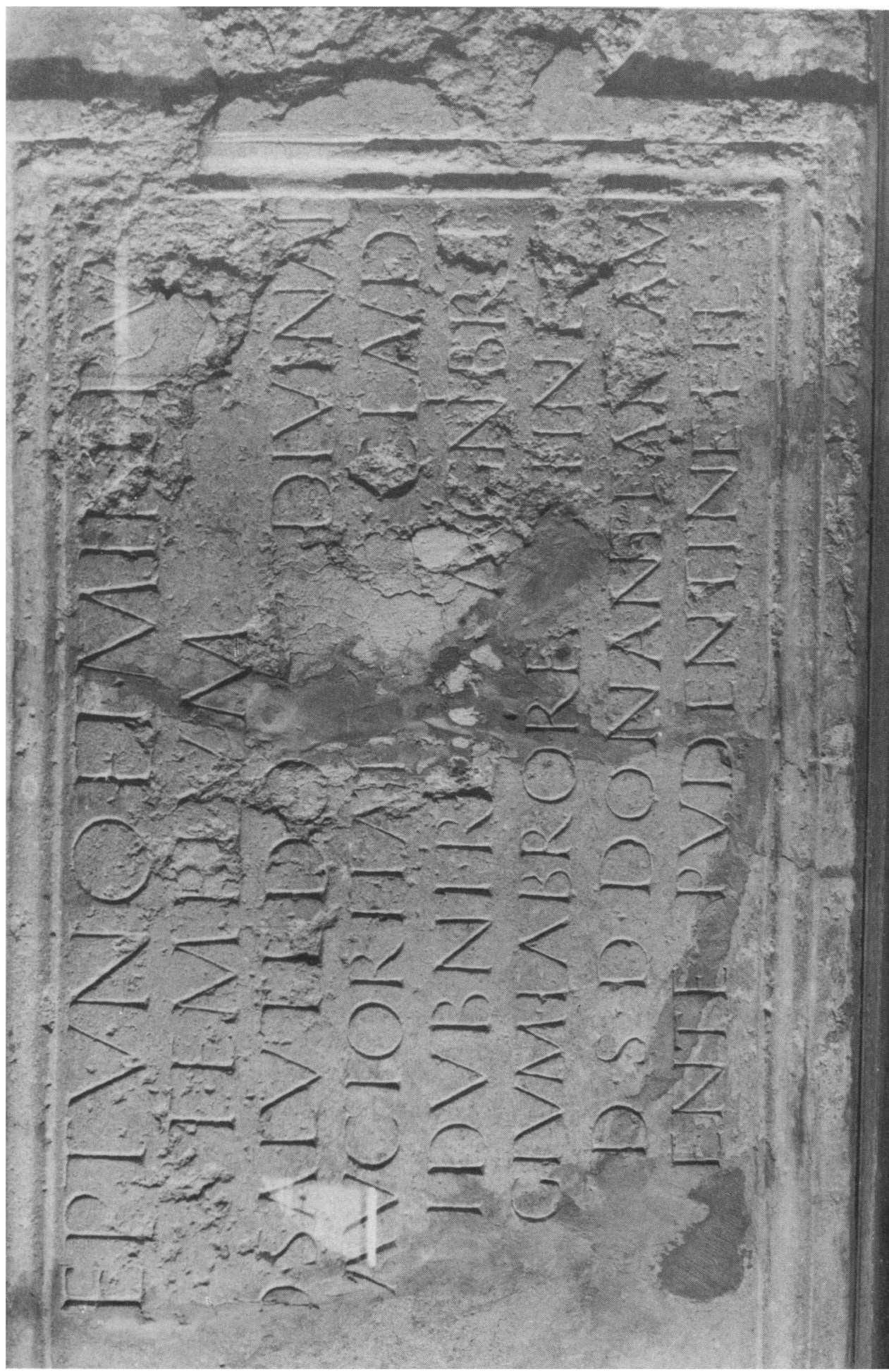


PLATE $X$

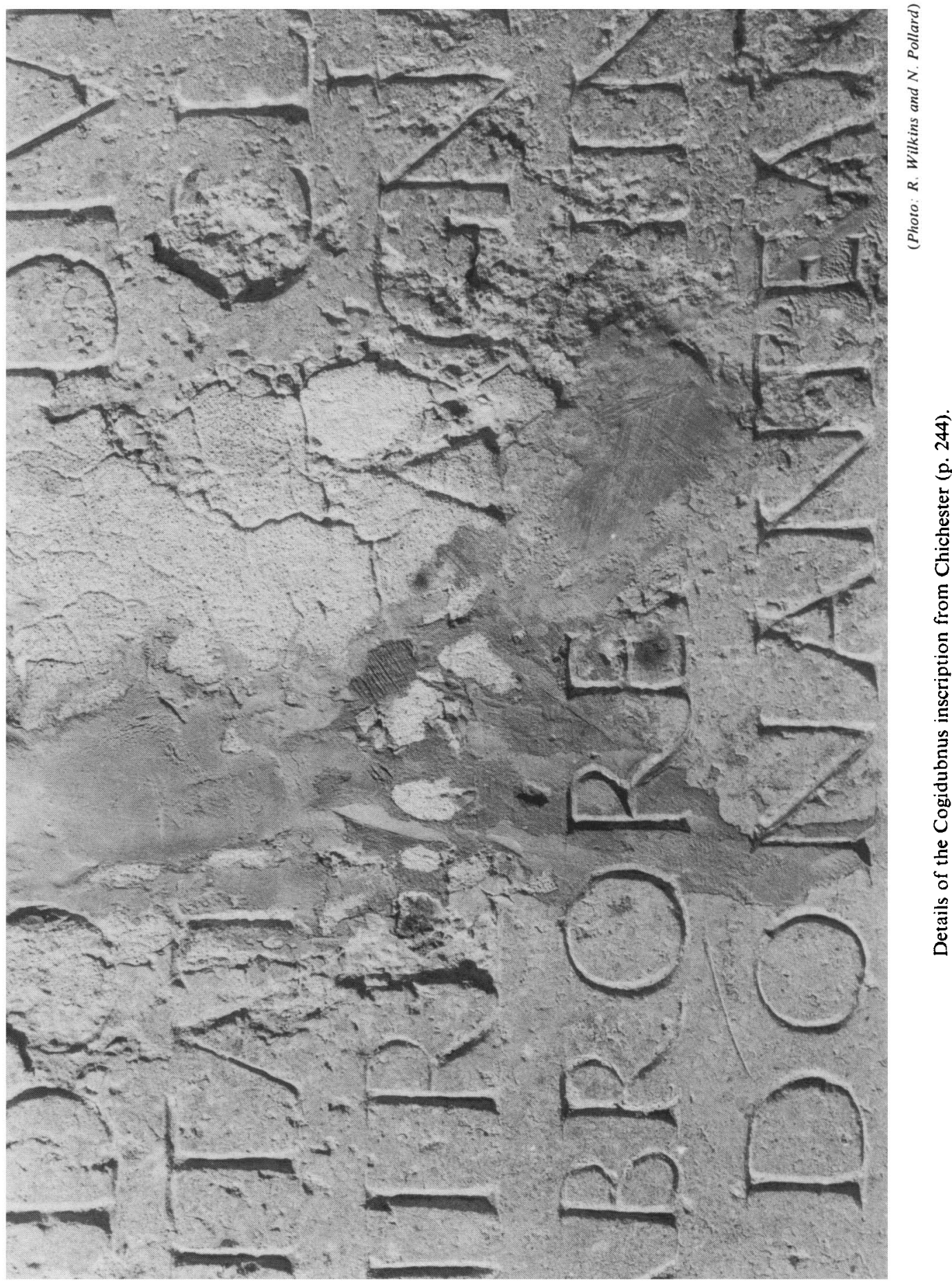


PLATE XI

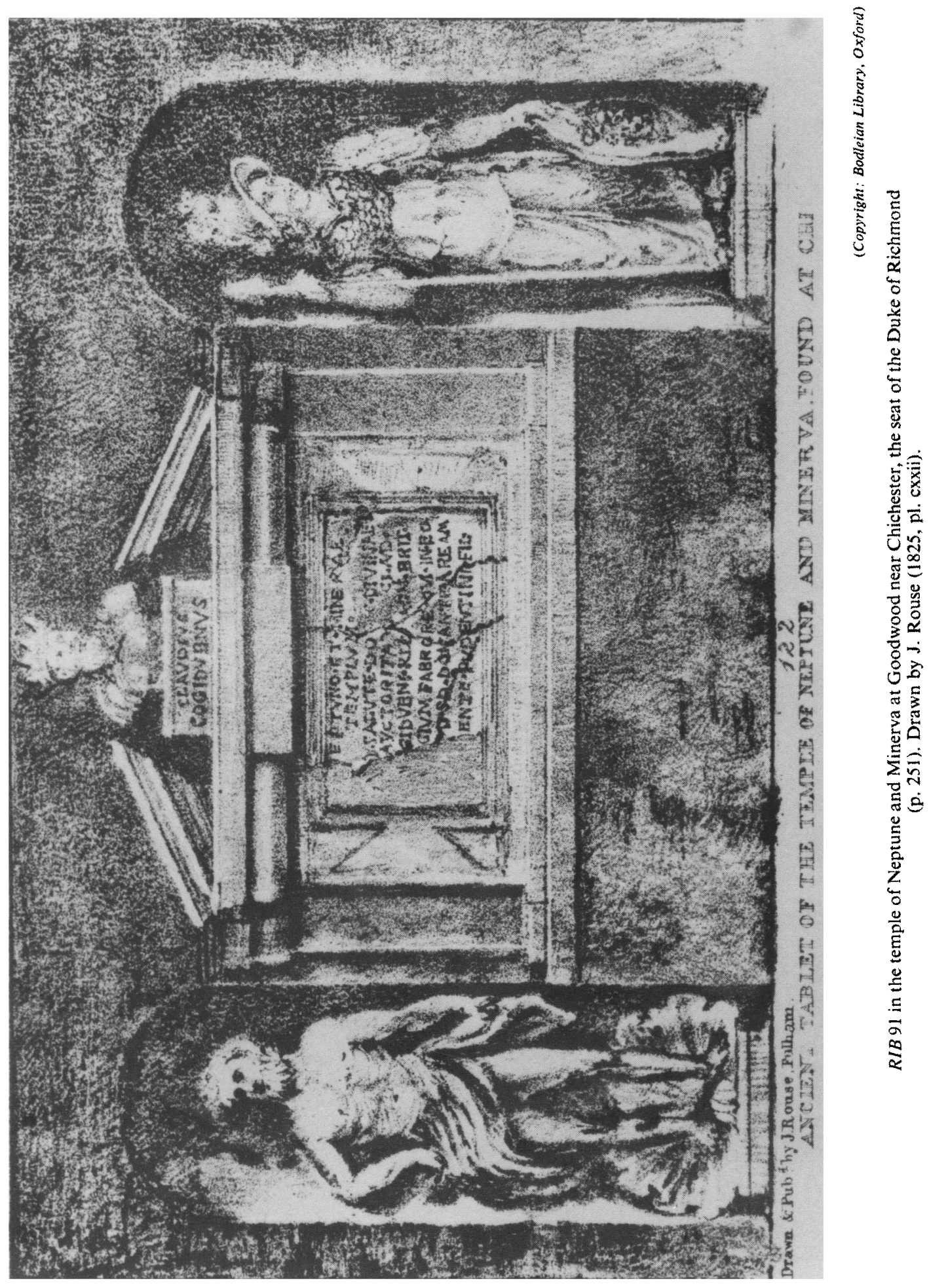


PLATE XII
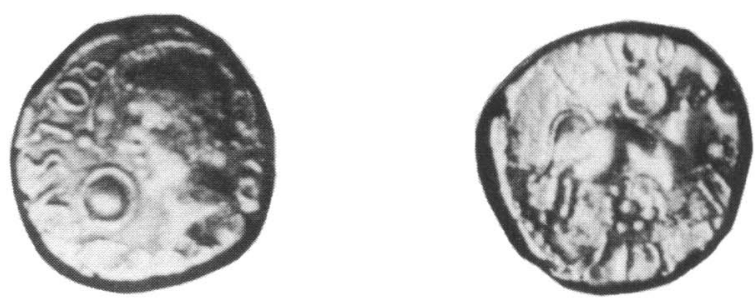

7
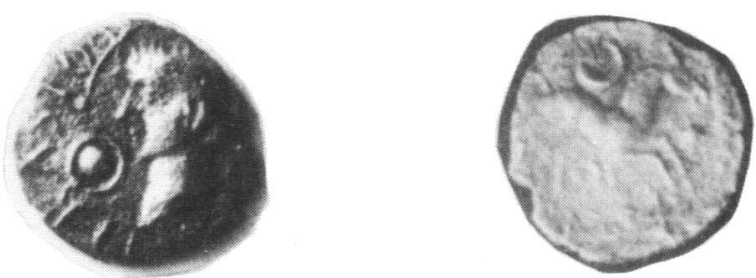

8
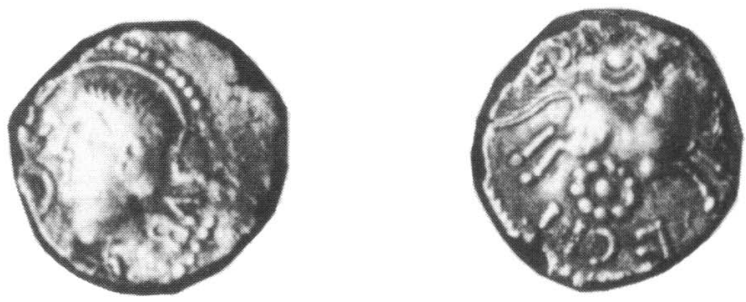

9
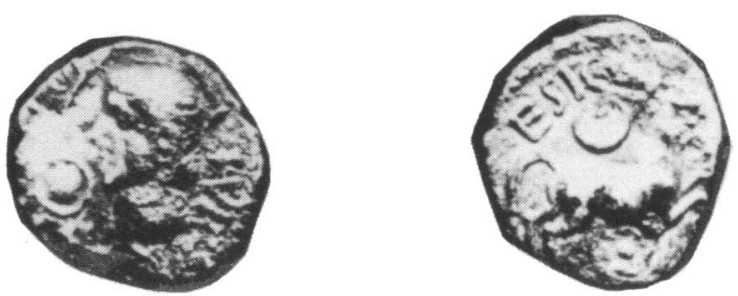

(Photo: H. R. Mossop)

Four Icenian silver coins inscribed SUBRI PRASTO/ESICO FECIT (p. 258). Scale 2:1. 


\section{PLATE XIII}

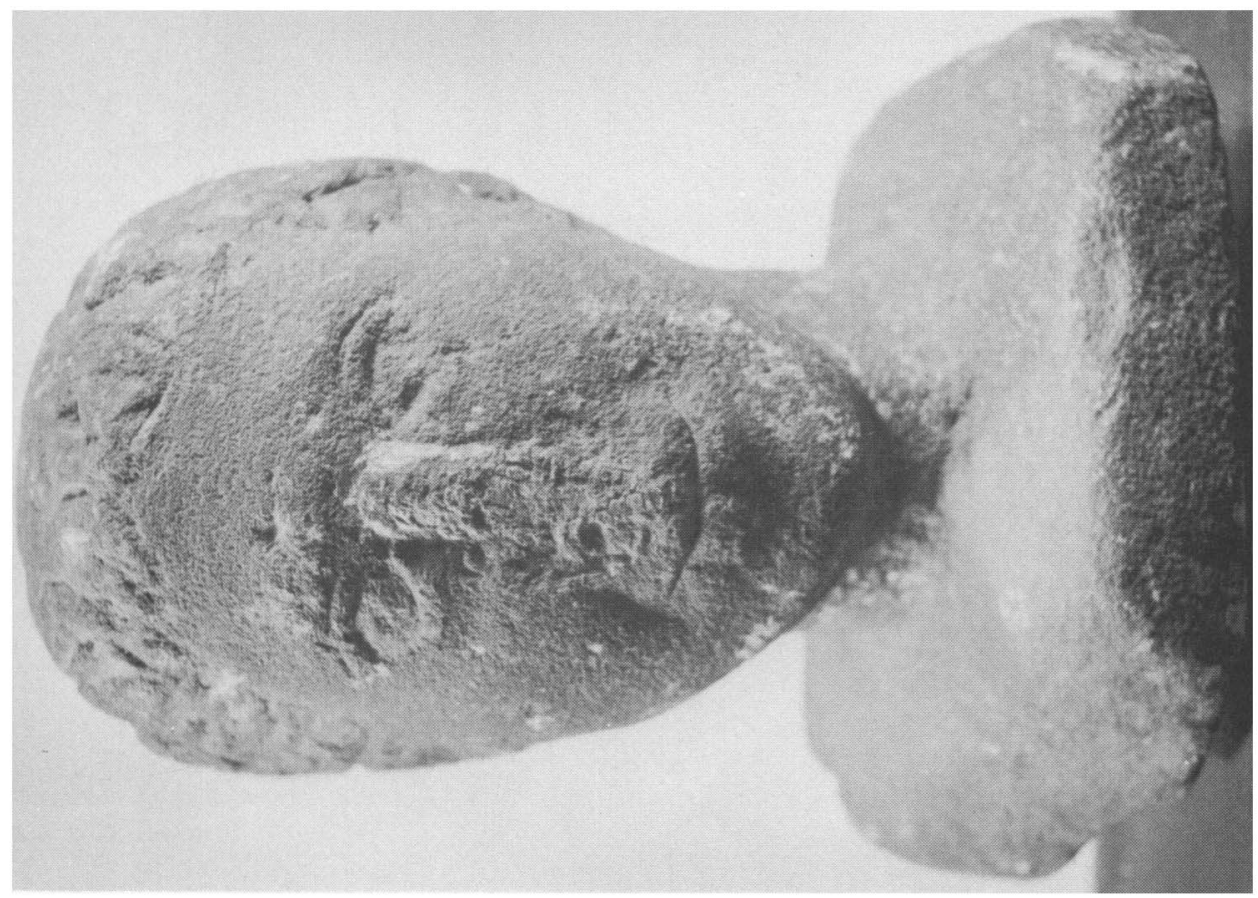

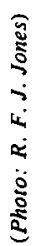

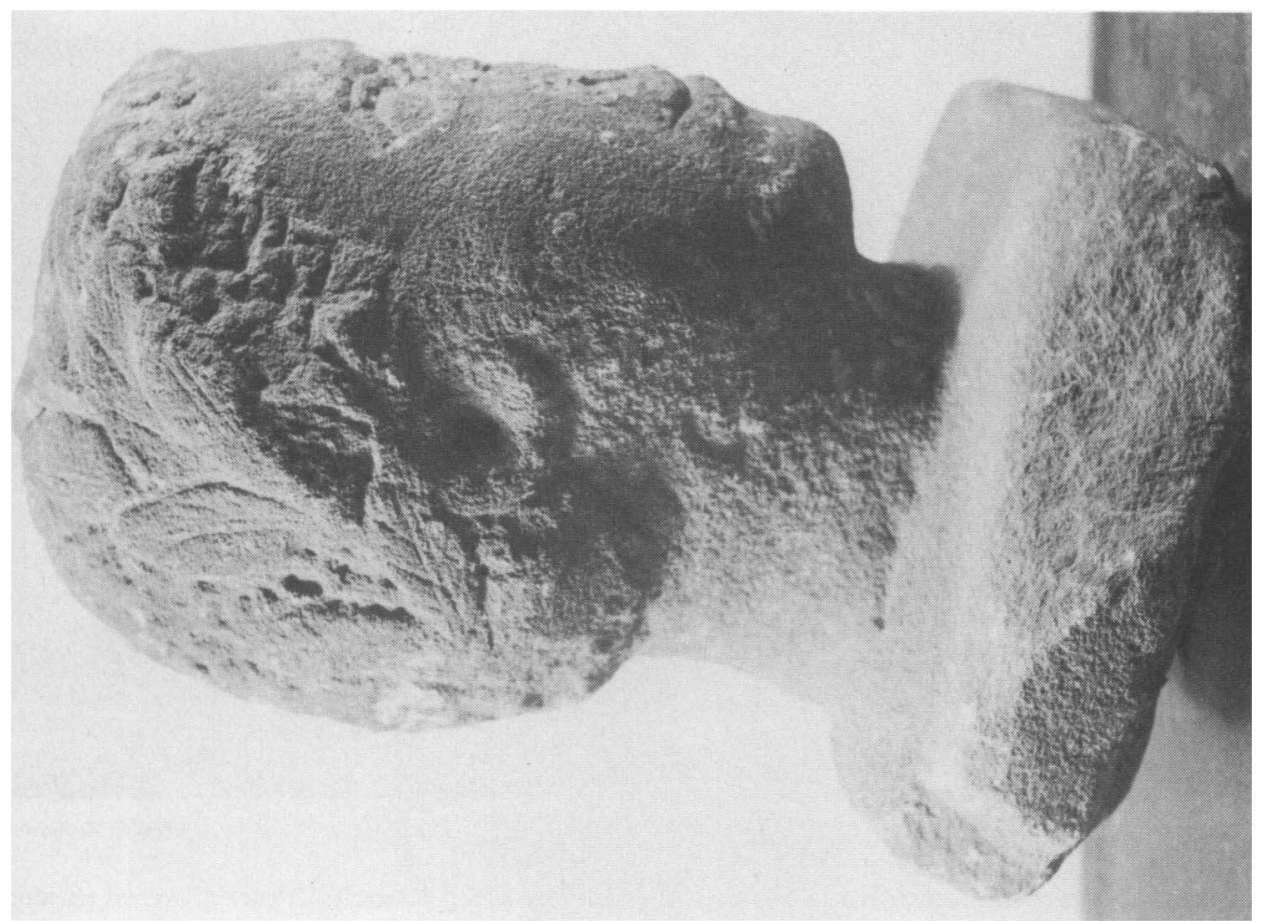

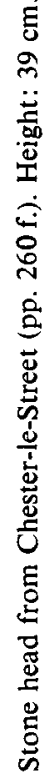




\section{PLATE XIV}

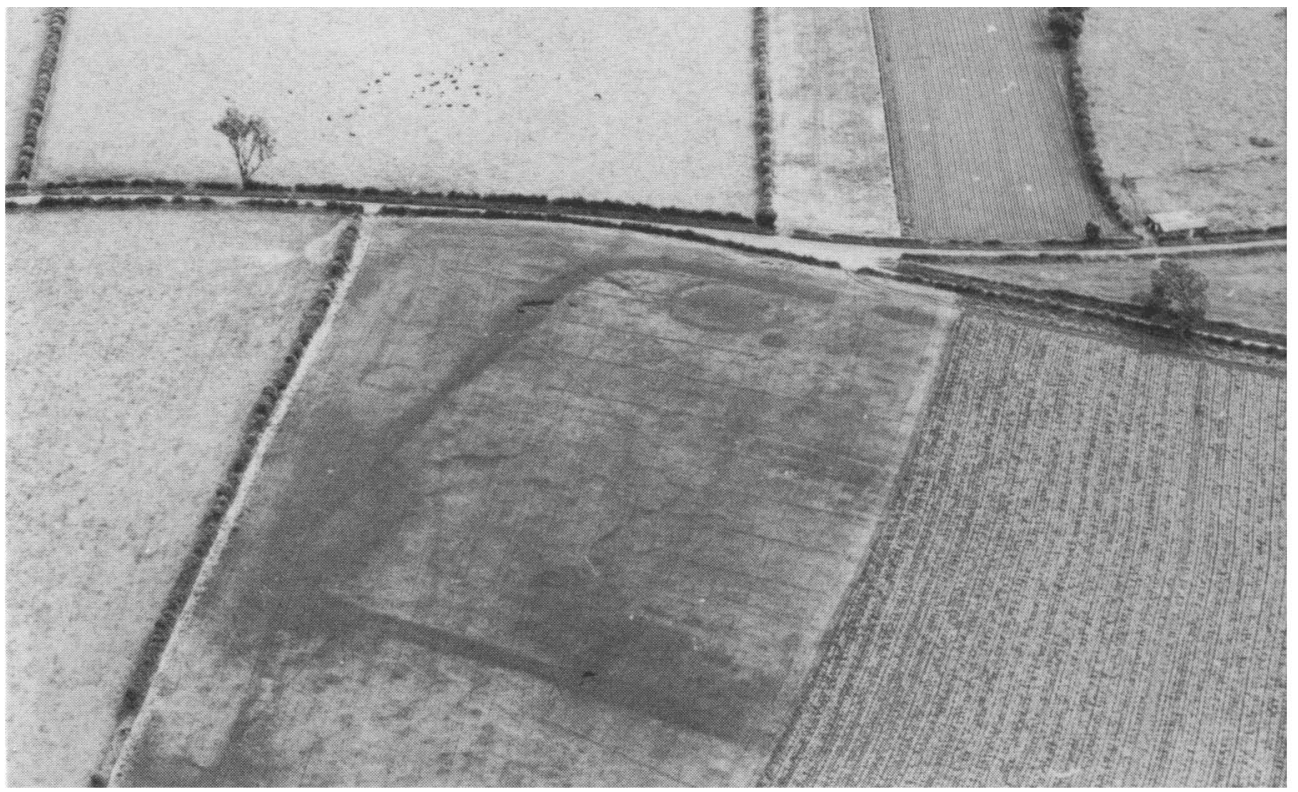

(Photo: G. D. B. Jones)

A. Burgh-by-Sands I: fort-site from W, with watch-tower near E side. View looking east (p. 281).

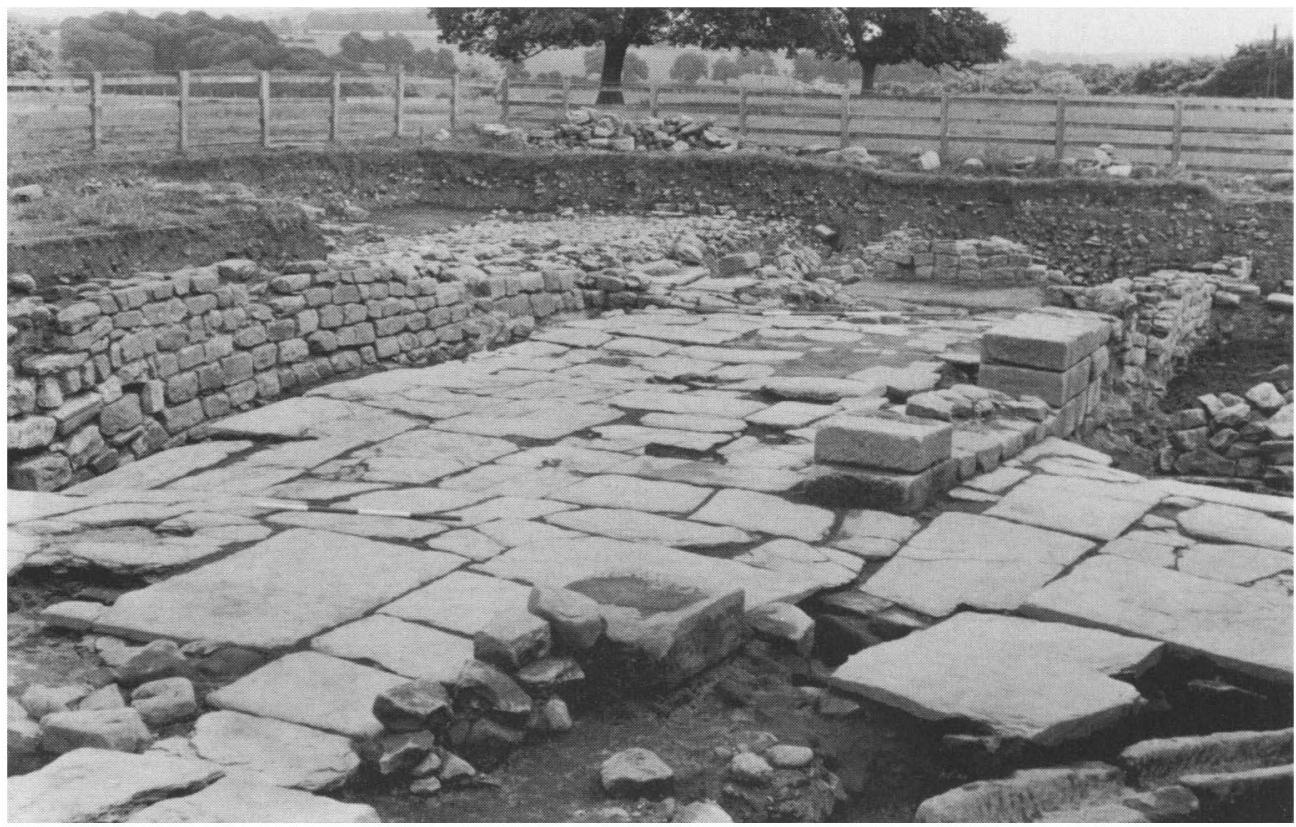

(Photo: Richard Jones)

B. Binchester, Co. Durham: fourth-century courtyard of Commander's House with part of arched entrance in foreground (p. 284). 


\section{PLATE XV}

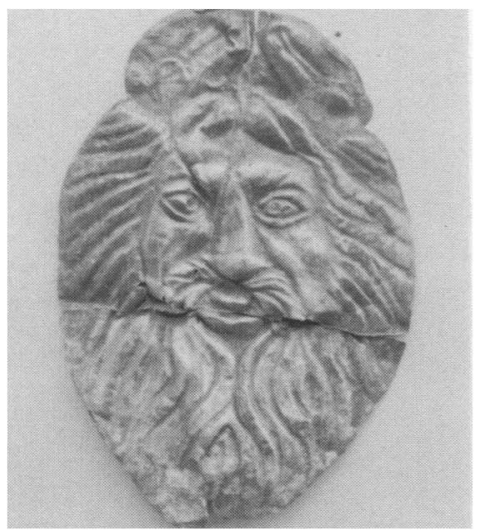

(Photo: A. E. Collins)

A. Great Chesterford, Essex: silver votive mask from the temple. Scale 1:2 (p. 309).

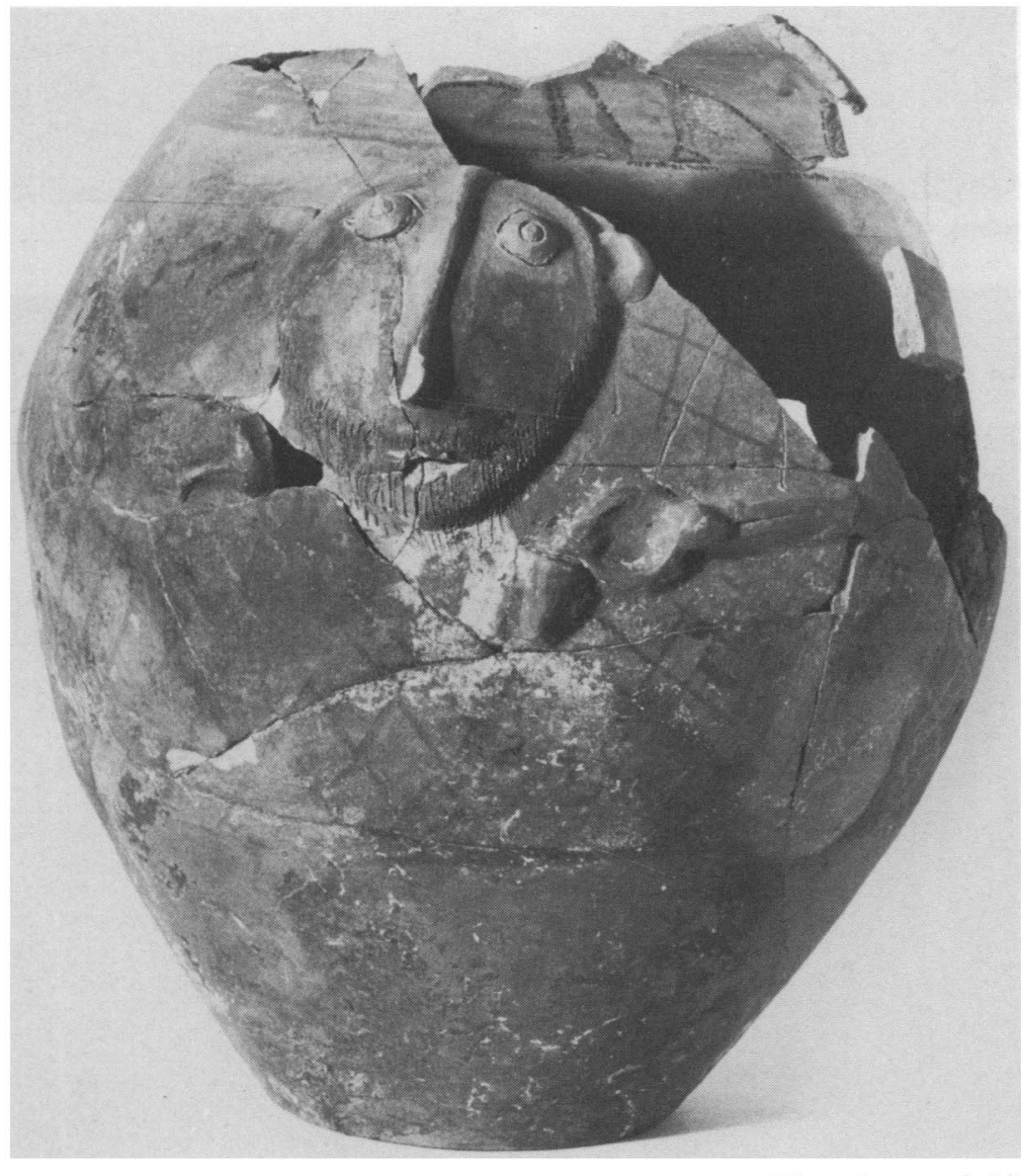

(Photo: Rosemary Smith)

B. Chester-le-Street, Co. Durham: face-pot containing bones of small dog (p. 285). 


\section{PLATE XVI}

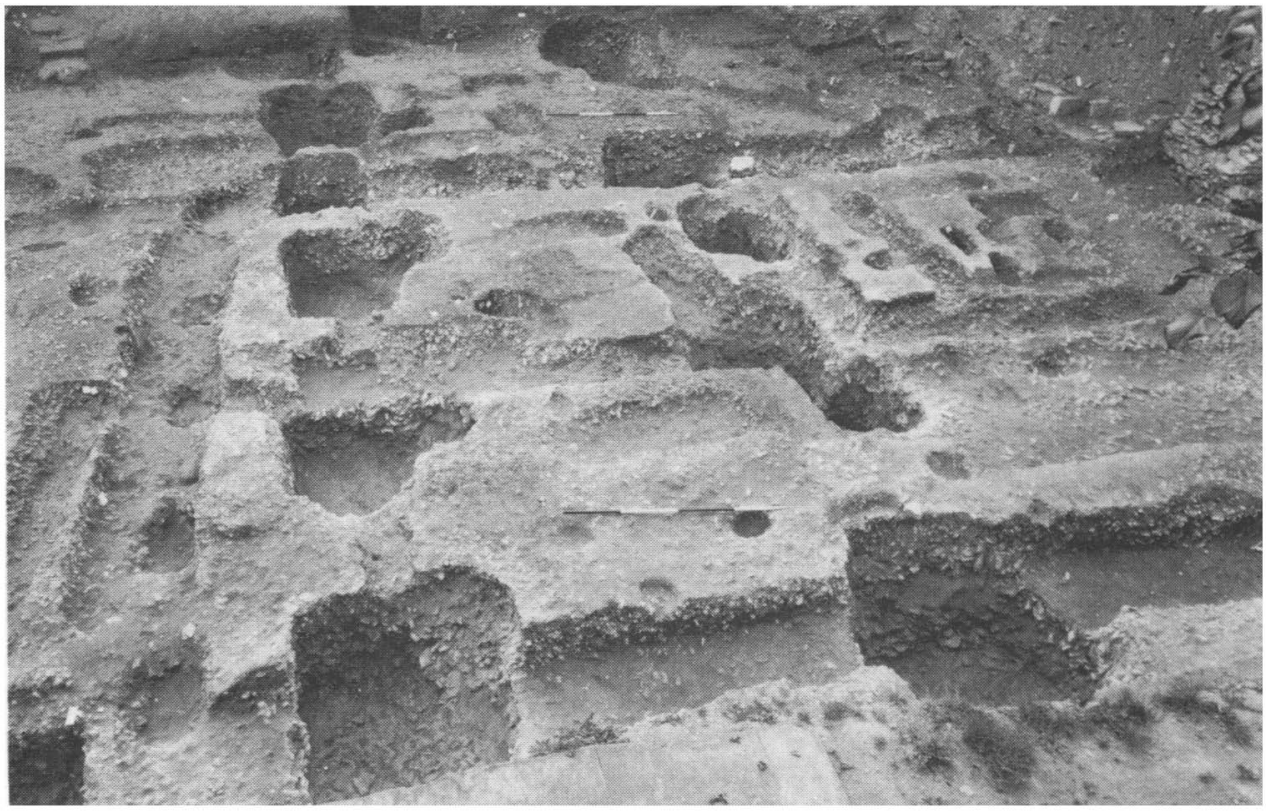

(Photo: H. N. Hawley)

A. Lincoln, St. Paul-in-the-Bail: double row of N-S post-holes representing the E aisle of the cross-hall of the principia, looking SSW (p. 294).

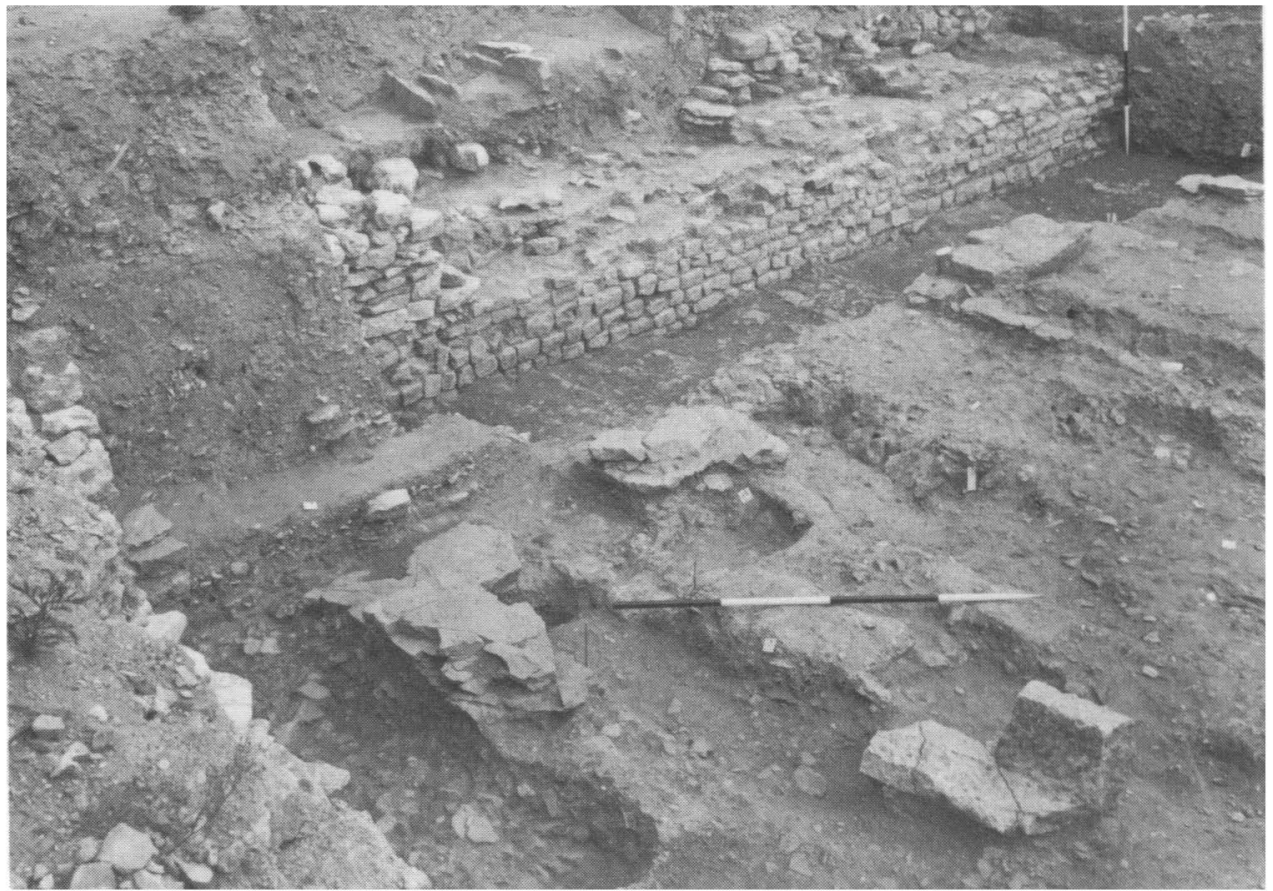

(Photo: H. N. Hawley)

B. Lincoln, St. Paul-in-the-Bail: wall and fragments of paving-slabs in forum courtyard, much disturbed by later graves (p. 294). Looking SE. 
PLATE XVII

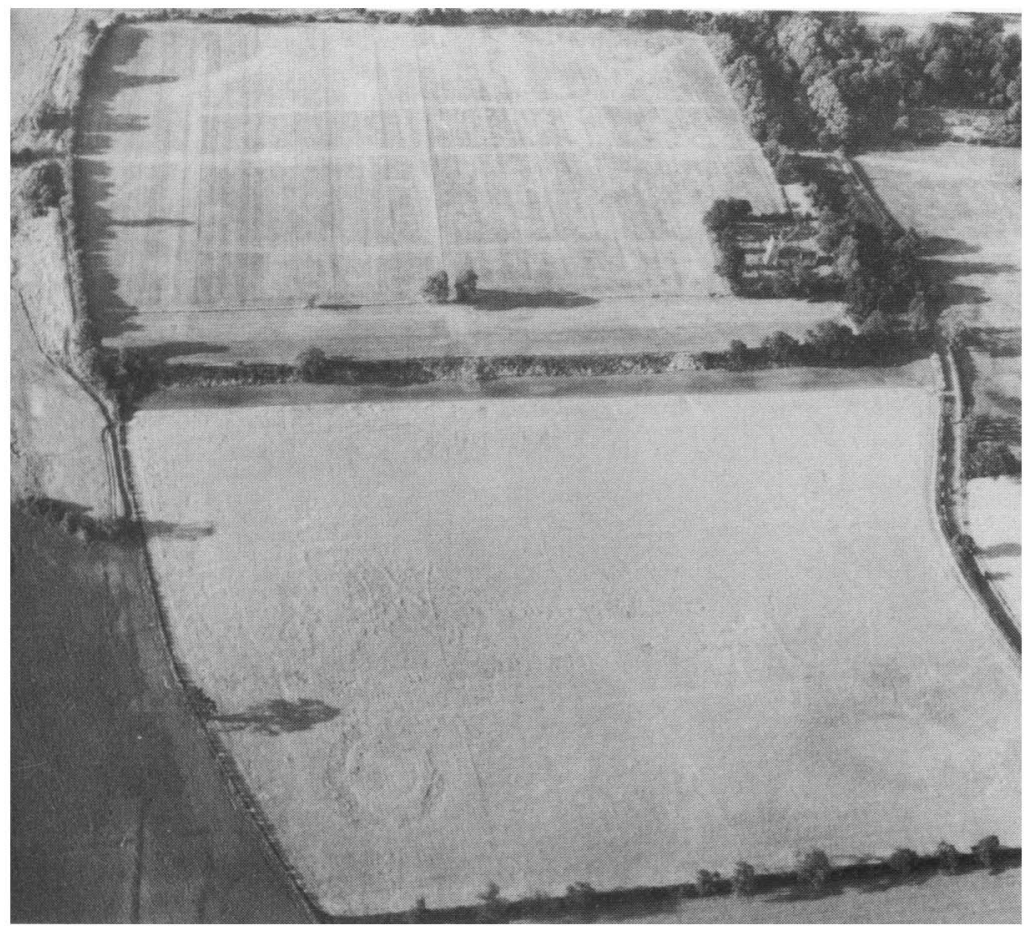

(Photo: E. A. Horne)

A. Caistor St. Edmund, Norfolk: crop-marks of features S of Venta Icenorum, looking N (p. 307).

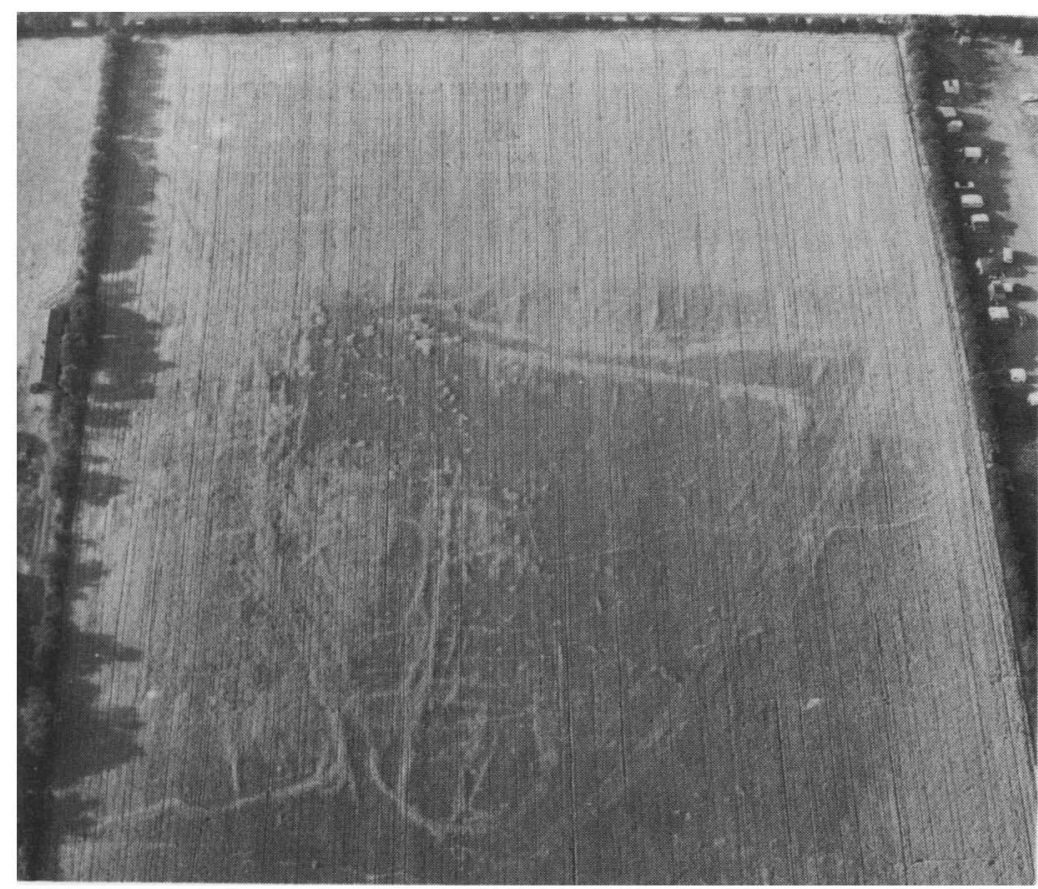

(Photo: E. A. Horne)

B. Burgh Castle, Suffolk: crop-marks of enclosures SE of the fort, looking N (p. 307). 


\section{PLATE XVIII}

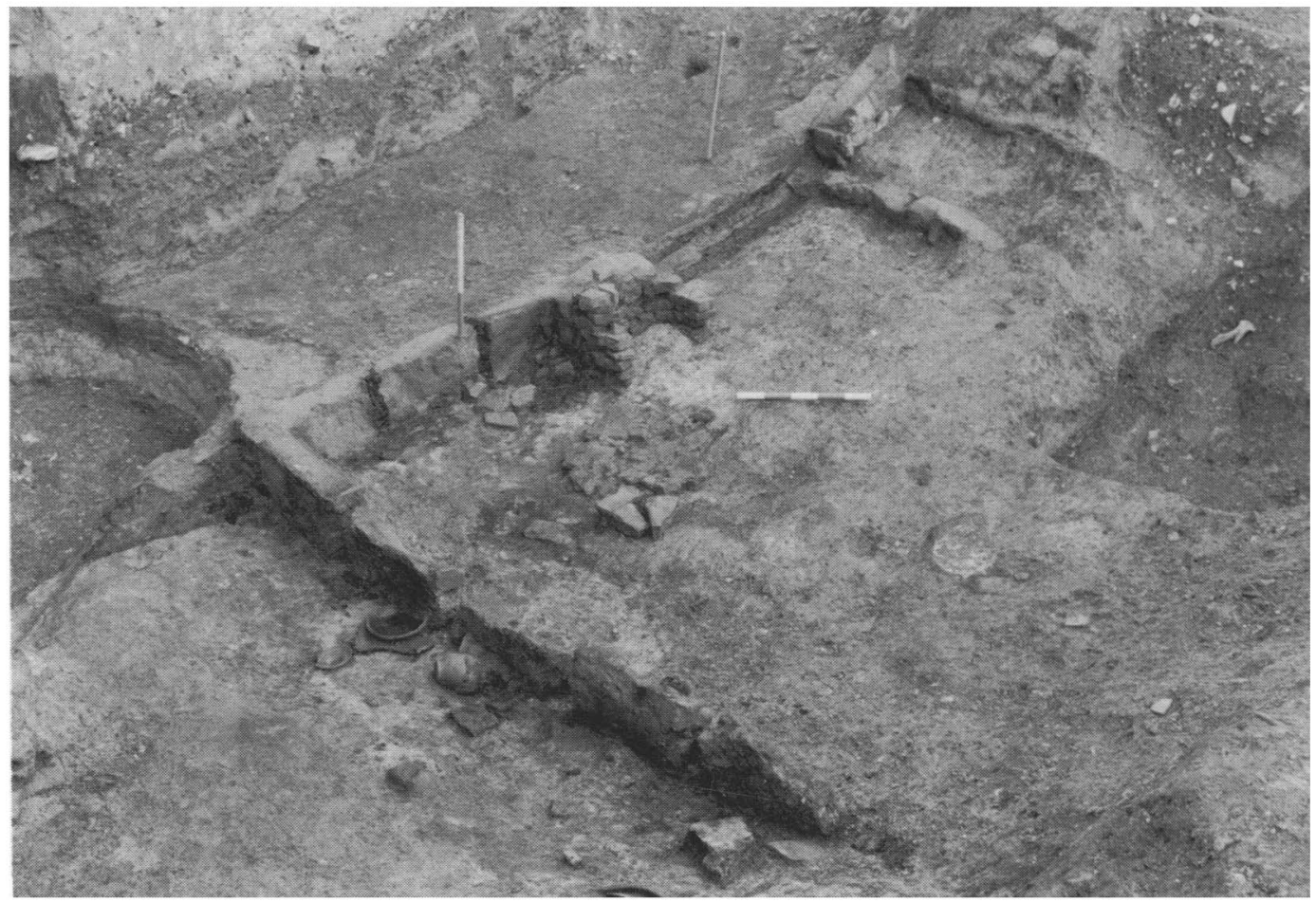

(Photo: $T$. Hurst)

A. London, G.P.O., Newgate Street: clay walls of northerly rooms in eastern early second-century building just before the Hadrianic fire, looking SE (p. 311).

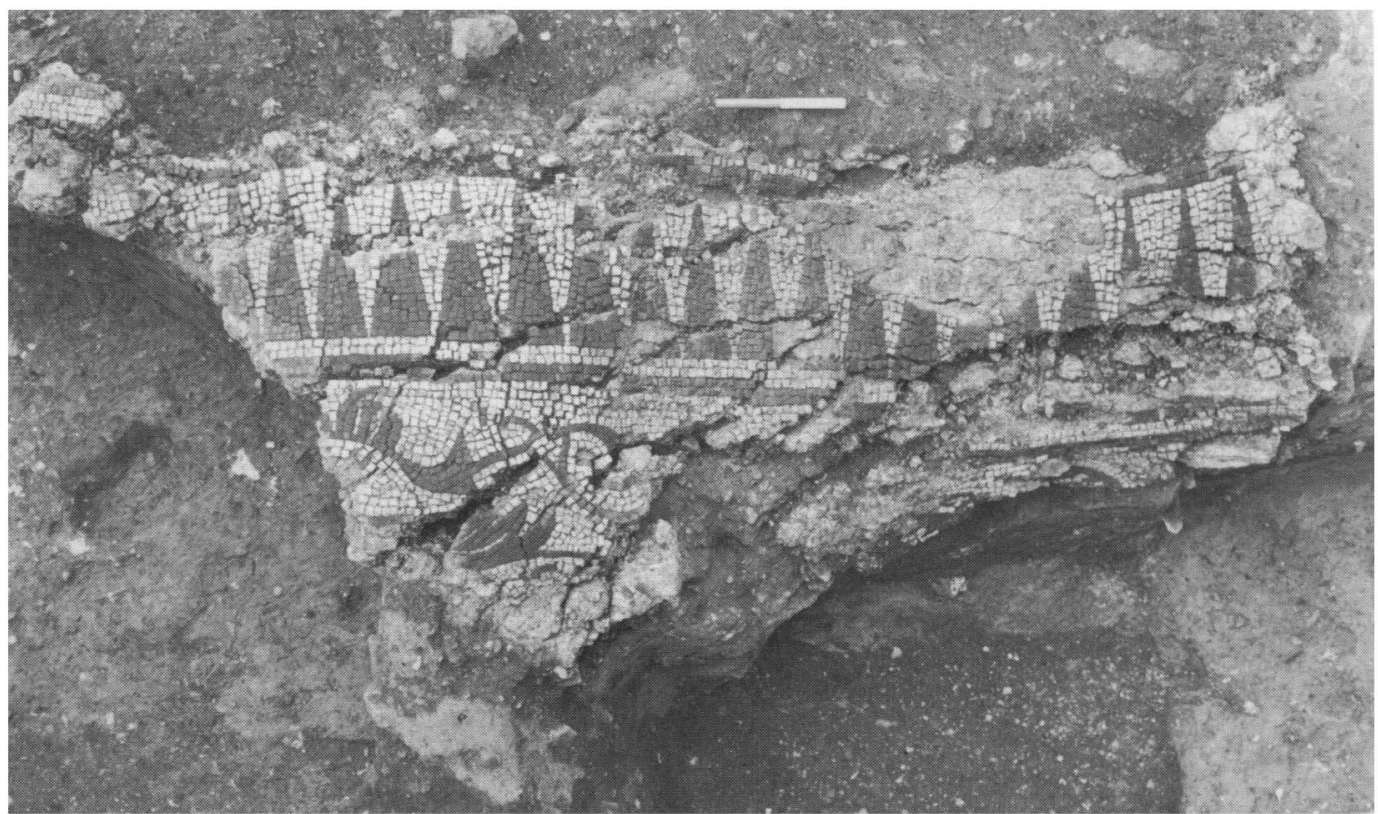

B. London, Watling Court: late first- or early second-century mosaic (p. 313). 


\section{PLATE XIX}

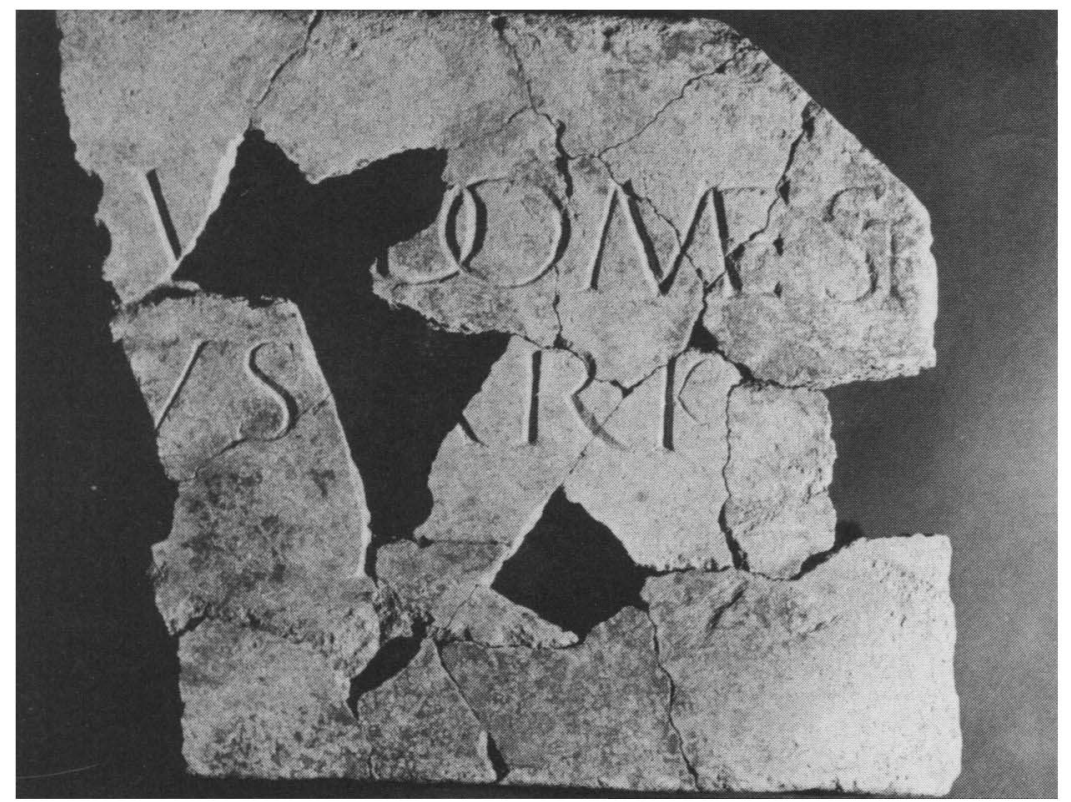

(Photo: Chichester Excavation Committee)

A. Chichester: inscribed slab (p. 339, No. 1). Scale 1:5.

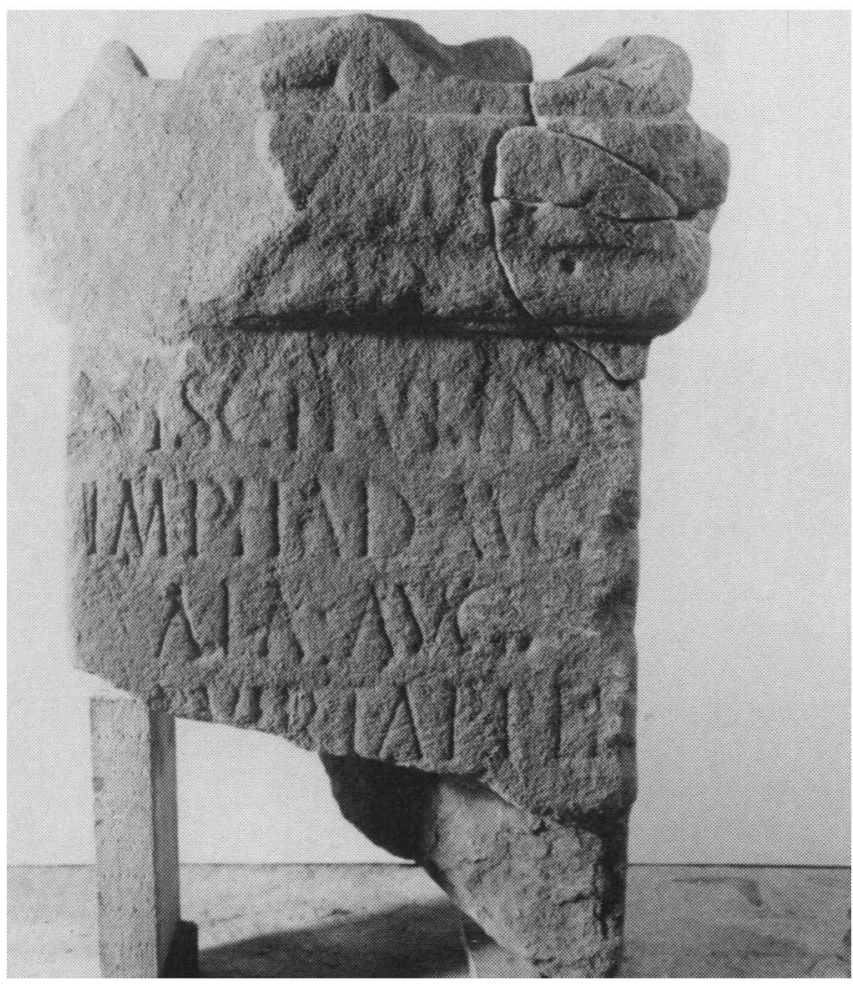

(Photo: Carlisle Museum and Art Gallery)

B. Chesters: inscribed altar (p. 346, No. 7). Scale 1:8. 


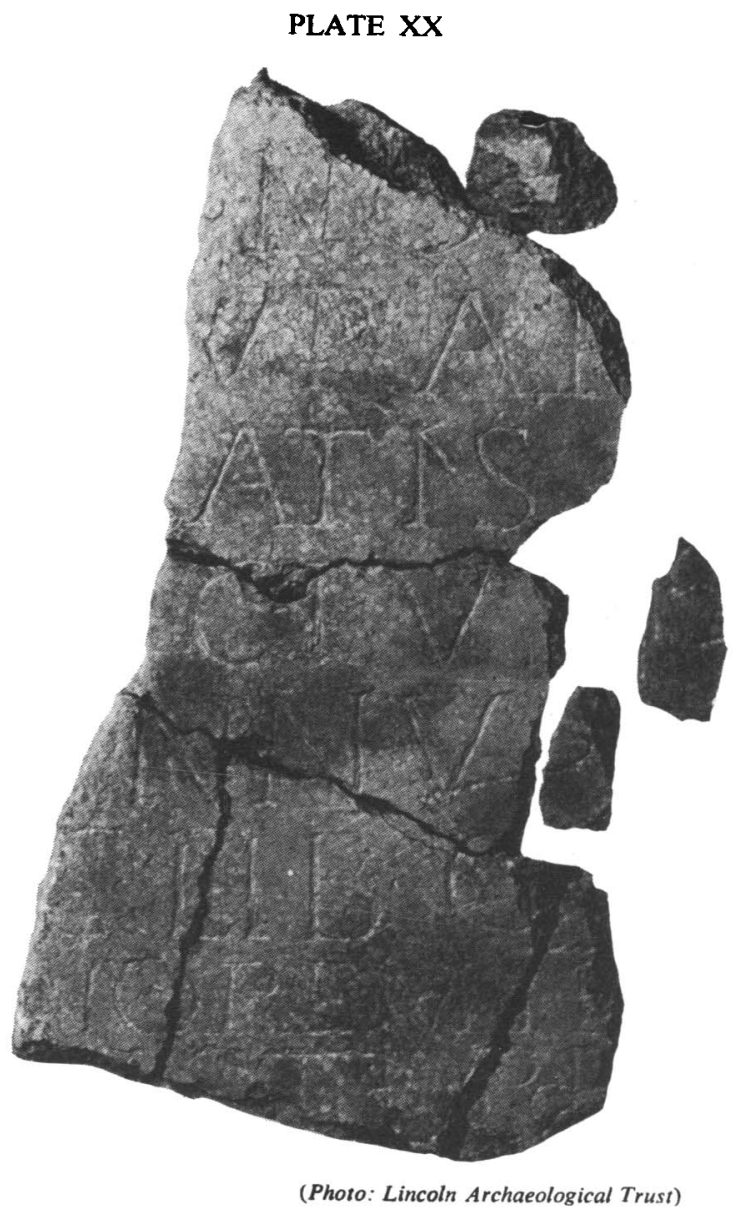

A. Lincoln: inscribed slab (p. 345, No. 5). Scale 1:4.

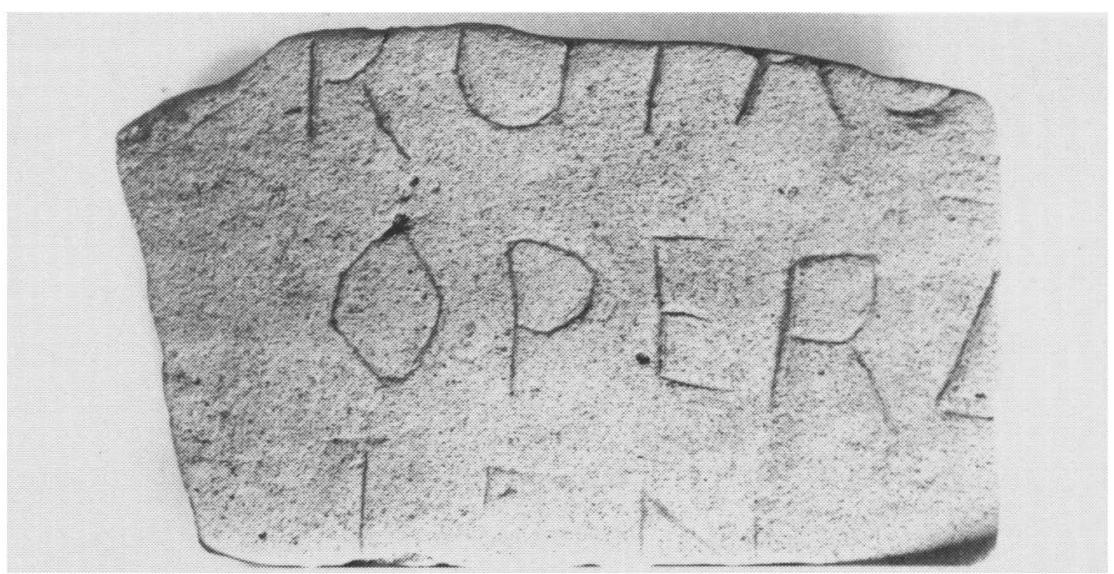

(Photo: Manchester University Department of Archaeology)

B. Manchester, Deansgate: inscribed amphora-sherd (p. 353, No. 34). Scale 1:2. 